\title{
Caryopsis Weight and Planting Depth of Blue Grama I. Morphology, Emergence, and Seedling Growth
}

\author{
C.J. CARREN, A.M. WILSON, R.L. CUANY, AND G.L. THOR
}

\section{Abstract}

Blue grama [Bouteloua gracilis (H.B.K.) Lag. ex Steud.] has been difficult to establish from seed on disturbed areas of the Central Plains. The objective of this study was to investigate the relationship of caryopsis weight, planting depth, and genetic variability on seedling emergence of blue grama. Two experiments were conducted in the greenhouse under favorable moisture conditions with 3 accessions and various combinations of caryopsis weight and planting depth. Messurements included rate of germination and emergence as an index, percentage emergence, shoot length, shoot weight, seminal root length, coleoptile length, subcoleoptile internode length and weight, adventitious root weight, and longest adventitious root length.

The length of the subcoleoptile internode increased in response to greater planting depth but weight per unit length decreased. If this indicates a decrease in internode diameter it could decrease the rate of water transport through the internode. Deep plantings were not advantageous to emergence or seedling growth under favorable soil moisture conditions and caused a delay in emergence and decreased percentage emergence, shoot weight, and adventitious root weight. High caryopsis weight was associated with an increase in emergence, weight per unit length of the subcoleoptile internode, coleoptile length, shoot weight, and adventitious root weight. Therefore, high caryopsis weight is advantageous in the deep planting of blue grama seeds and allows seeds to be planted deeper to take advantage of moisture for germination and emergence.

Key Words: seed weight, Bouteloua gracilis, adventitious roots, seedling morphology, path analysis, seedling establishment

Blue grama [Bouteloua gracilis (H.B.K.) Lag. ex Steud.] is the dominant native grass of the Central Plains of the United States.

\footnotetext{
Authors are lab assistant, Dept. of Agronomy, Colorado State Univ., Fort Collin 80523; plant physiologist (deceased), USDA, ARS, Crops Research Lab., Colorado State Univ., Fort Collins 80523; professor and researcher, Dept. of Agronomy, Colorado State Univ., Fort Collins 80523.

The authors wish to thank Phillip Morrisey and Patricia Fashing for technical assistance in the study.

The authors thank Dr. M.A. Brick and Dr. C.H. Pearson of the Department of Agronomy; Dr. M.J. Trlica of the Department of Range Science; Dr. P. Coyne of the USDA Southern Great Plains Range Research Station, Woodward, OK; and Dr. D.D. Briske of Texas A\&M University, College Station for their comments in reviewing this paper.

Manuscript accepted 3 November 1986.
}

There are, however, about 5 million acres of abandoned cropland in the Central Plains on which blue grama has not become naturally reestablished during the 40 to 50 years since cultivation ceased (Bement et al. 1965).

The difficulty of establishment of blue grama from seed in range plantings is related to several factors, including: small seed size, the presence of a single branched (but thin) seminal root, a thin subcoleoptile internode which must transport all water necessary for seedling survival, a short coleoptile, and the location of the crown near the soil surface (Hyder et al. 1971, Nason et al. 1987) (Fig. 1).

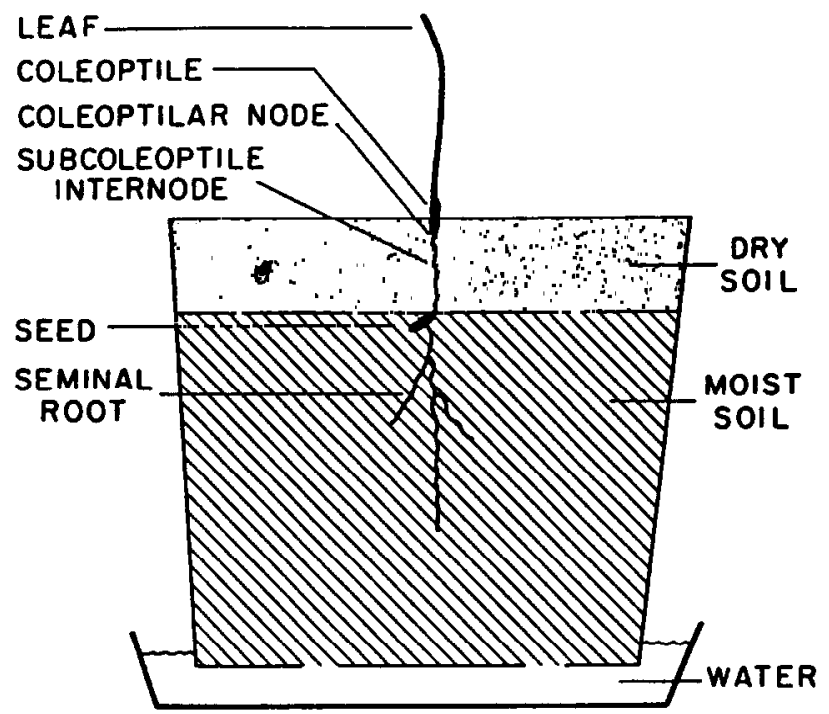

Fig. 1. Diagram of blue grama seedling that has emerged through dry soil layer. The coleoptilar node is the site of adventitious root formation.

The plant will not survive if the seminal root is killed by desiccation before adventitious roots are established, because new seminal roots cannot be formed. Adventitious roots will only develop and grow when soil at the plant's crown is moist for approximately 3 
days after the plant has reached at least 2 weeks of age (Wilson and Briske 1979). If the drying front of the soil progresses downward faster than the new adventitious roots extend themselves, the plant will probably die from desiccation in the unsuccessful attempt at adventitious rooting.

In other grass species, improved vigor and ability to emerge from deep plantings are often associated with heavier seeds (Rogler 1954, Kneebone and Cremer 1955, Tossell 1960, Arnott 1969, Knipe 1970, Trupp and Carlson 1971, Wright 1977). Wilson et al. (1981) concluded that caryopsis weight is a genetic characteristic in blue grama and therefore it is possible to select and improve the species for high caryopsis weight.

The objective of this study was to investigate the relationship of caryopsis weight, planting depth, and accession on seedling emergence, morphology, and growth of blue grama.

\section{Materials and Methods}

\section{Morphology Experiment}

Three blue grama accessions were used: 2 released cultivars, 'Hachita' and 'Lovington', originated from seed collected south of Hachita and near Lovington in SW and SE New Mexico, respectively. The third was a composite, PM-K-1483, of accessions from Kansas and Texas that was maintained by the Soil Conservation Service (SCS). All 3 accessions come from regions of the Great Plains with more precipitation and a greater number of degree days than are found near Fort Collins, Colo. Spikelets (seeds) of these 3 accessions were harvested in 1978 in related research (Wilson et al. 1981) from individual plants in a 1080-plant nursery located at the SCS, Plant Materials Center, Los Lunas, New Mexico. Average caryopsis weight of the seeds from each plant was determined, and each plant was assigned to 1 of 5 caryopsis weight classes (35-40, $40-45,45-50,50-55$, and $55-60 \mathrm{mg} / 100$ caryopses, designated as class 1 through 5, respectively). The spikelets were processed with a South Dakota seed blower to eliminate unfilled spikelets.

An equal quantity of seed from 10 plants within each of the 3 accessions and the 5 weight classes was taken to form 15 seed lots. Each seed lot was planted in pots at each of 3 depths $(1.0,2.0$, and $3.0 \mathrm{~cm}$ ), which resulted in 45 pots $(3$ accessions $X 5$ weight classes $X$ 3 planting depths) in each of 7 replications. Plastic pots $(15 \mathrm{~cm}$ diameter and $15 \mathrm{~cm}$ height) were filled with $1,600 \mathrm{~g}$ of sterilized, screened McGrew sandy loam soil (fine-loamy, mixed, mesic Aridic Argiustoll). Fifteen seeds were spaced evenly on the soil surface in each pot, covered with $50 \mathrm{~g}$ of soil (approximately 0.2 $\mathrm{cm}$ ), irrigated with $250 \mathrm{ml}$ of water to bring the soil to field capacity (about $-0.03 \mathrm{MPa}$ ), and then covered with enough dry soil to obtain $1.0,2.0$, or $3.0-\mathrm{cm}$ planting depths. Pots were subirrigated as necessary (determined by weight) to maintain field capacity up to the planting depth, but seedlings were required to emerge through a dry soil layer (Fig. 1). Moisture rose a few millimeters into the dry soil but because of the irrigation procedure this soil layer remained dry. Pots were maintained in the greenhouse with 14 hours of supplemental sodium vapor lighting and 25 to $35^{\circ} \mathrm{C}$ temperatures. The soil was washed from the seminal roots of seedlings 10 days after planting. If more than 10 seedlings emerged in a pot, the excess seedlings were randomly eliminated. Measurements were taken on shoot length (coleoptilar node to the tip of the longest leaf), seminal root length, coleoptile length, subcoleoptile internode length, and subcoleoptile internode weight. Weight per unit length of the subcoleoptile internode (which may be an indication of its diameter) was calculated.

\section{Emergence and Seedling Growth Experiment}

In this experiment, plants belonging to the same accessions described earlier were divided into 6 caryopsis weight classes by adding a 60 to $70 \mathrm{mg} / 100$ caryopses class to the 5 classes previously described. Spikelets harvested from 3 separate plants within each accession and weight class were used. Twenty-five spikelets from each of the 3 plants per weight class and accession were planted per pot, at each of 6 different soil depths $(2.0,2.5,3.0,3.5,4.0$, and 4.5 $\mathrm{cm}$ ) for a total of 324 pots ( 3 accessions $\times 6$ weight classes $\times 3$ plants $\times 6$ planting depths) in each of 4 replications. The planting method was similar to that used in the morphology experiment (Fig. 1) and prevented adventitious root development by maintaining the dry soil layer above the seed.

From the third day to the tenth day after seeds were planted, the number of seedlings that emerged each day was recorded. A rate of emergence index was calculated using the formula:

$$
\frac{(\Sigma n) \times 100}{\Sigma(n \times D)}
$$

where $\mathbf{n}=$ number of seedlings that emerged on each day and $D=$ the number of days after planting (Kotowski 1926, Maguire 1962). This formula provides for an index that is expressed in reciprocal days and is independent of the total number of plants that emerged. A high index indicates early emergence. A rate of germination index was calculated by applying the above formula to the daily germination data from a 10 -day, $25^{\circ} \mathrm{C}$ blotter paper germination test of spikelets from the same 54 parent plants. The percentage of emerged seedlings was calculated by dividing the total that emerged by the total number of germinable seeds planted (based on the germination test).

Seedlings were randomly thinned to 3 per pot after 3 weeks, and subirrigated as needed (by weight) to maintain field capacity of the bottom moist soil layer for approximately 6 weeks while the plants subsisted solely on their seminal roots. Then adventitious root growth was promoted by covering the crowns of seedlings with 1 $\mathrm{cm}$ of screened soil and surface irrigating daily to maintain the entire pot at field capacity. After 3 days, soil was washed from the plants and 3 growth characteristics were measured: length of longest adventitious root, dry weight of shoots, and dry weight of adventitious roots. The data for each pot was the mean of those seedlings which had emerged and survived to the end of the test.

Statistical analyses for the 2 experiments included an analysis of variance on each of the variables investigated (including all possible interactions; if no interaction is mentioned, the interaction was not significant); Duncan's multiple range test to separate significant accession and parent plant differences; and multiple regression of subcoleoptile internode weight per unit length on caryopsis weight and planting depth. Analysis of covariance for percent emergence, with caryopsis weight as the covariate, was used to determine if there were differences among parent plants and planting depths after adjusting for the effects of different caryopsis weights. Simple bivariate correlations were calculated between selected factors and variables. Standardized partial regression coefficients or path coefficients (p) (Wright 1934, Nie et al. 1975) were calculated to determine the relative effects of planting depth and caryopsis weight on subcoleoptile weight per unit length.

Cause-and-effect assumptions (based on the developmental sequence in blue grama) were made among the variables of adventitious root weight, and caryopsis weight, planting depth, germination index, emergence index, and final shoot weight. Data from the experiment were subjected to path coefficient analysis (Wright 1934, Nie et al 1975) to determine statistical significance of those assumed cause-and-effect relationships.

\section{Results and Discussion}

\section{Morphology Experiment}

Increased planting depth shoot length and likewise seminal root root length (table 1). Increased planting depth also decreased the weight per unit length of the subcoleoptile internode. Conversely, increased planting depth increased coleoptile length slightly and subcoleoptile internode length considerably (Table 1). Even though these coleoptile differences were statistically significant, they may not be biologically meaningful because a fraction of a millimeter probably would not affect seedling establishment.

Increased caryopsis weight was associated with increased shoot length, increased weight per unit length of the subcoleoptile inter- 
Table 1. Effect of planting depth on seedling traits'

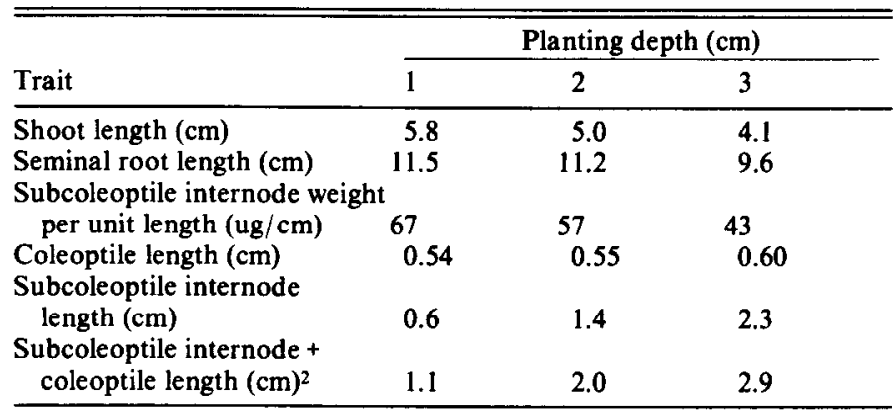

Differences among plant depths were significant for all traits $(P \leq 0.01)$

${ }^{2}$ Subcoleoptile internode length + coleoptile length is approximately equal to planting depth.

node, and increased coleoptile length (Table 2). The frequency of coleoptiles with a length greater than $0.70 \mathrm{~cm}$ was more than 3 times greater in the highest weight class than in the lowest weight class. Seedlings from the 5 caryopsis weight classes differed in seminal root length but not in a consistent pattern.

Table 2. Effect of caryopsis weight on seedling traits' ${ }^{1}$.

\begin{tabular}{lccccc}
\hline \hline & \multicolumn{5}{c}{ Caryopsis weight class } \\
\cline { 2 - 6 } Trait & 1 & 2 & 3 & 4 & 5 \\
\hline Shoot length (cm) & 4.6 & 5.0 & 5.1 & 4.9 & 5.5 \\
Seminal root length (cm) & 10.2 & 11.2 & 11.0 & 10.6 & 11.0 \\
$\begin{array}{l}\text { Subcoleoptile internode } \\
\quad \text { weight per unit length (ug/cm) }\end{array}$ & 51 & 55 & 54 & 60 & 60 \\
Coleoptile length (cm) & 0.54 & 0.56 & 0.56 & 0.57 & 0.59 \\
\hline
\end{tabular}

'Differences among caryopsis weight classes were significant for all traits $(p \leq 0.01)$.

Hachita had a greater shoot length than the other 2 accessions (Table 3). Accession PM-K-1483 had longer seminal roots than did the other 2 accessions. Although the accessions did not differ in subcoleoptile internode length, Hachita had the longest coleoptiles (Table 3).

Table 3. Efrect of accession on seedling traits ${ }^{1}$.

\begin{tabular}{lccc}
\hline & \multicolumn{3}{c}{ Accession } \\
\cline { 2 - 4 } Trait & Hachita & Lovington & PM-K-1483 \\
\hline Shoot length (cm) & $5.4^{\mathrm{a}}$ & $4.8^{\mathrm{b}}$ & $4.8^{\mathrm{b}}$ \\
Seminal root length (cm) & $10.6^{\mathrm{b}}$ & $10.6^{\mathrm{b}}$ & $11.2^{\mathrm{a}}$ \\
Coleoptile length $(\mathrm{cm})$ & $0.58^{\mathrm{a}}$ & $0.56^{\mathrm{b}}$ & $0.56^{\mathrm{b}}$ \\
\hline
\end{tabular}

'Means for a particular trait having the same letter were not significantly different ( $P>0.05$ according to Duncan's multiple range test.

Regression analysis indicated that an increase in caryopsis weight was associated with increased weight per unit length of the subcoleoptile internode (path coefficient, $p=0.15$ ), whereas increased planting depth was associated with decreased weight per unit length of the internode $(p=-0.49)$. This indicated the opposing influences of the 2 independent variables.

\section{Emergence and Seedling Growth Experiment}

A deep planting depth dramatically decreased the emergence of seedlings, but a greater caryopsis weight was associated with increased emergence (Fig. 2). Emergence ranged from a low of $1 \%$ at the $4.5-\mathrm{cm}$ depth for weight class 1 to a high of $98 \%$ at the $2.0-\mathrm{cm}$ depth for weight class 6 . Accessions PM-K-1483 and Hachita were superior to Lovington in percentage emergence with mean values of 59,60 , and $55 \%$, respectively, over all depths and weight classes.

Different average emergence percentages were noted among seedlings from the 54 parent plants, which ranged from 30 to $76 \%$. The correlation coefficient $(r)$ between caryopsis weight and per-

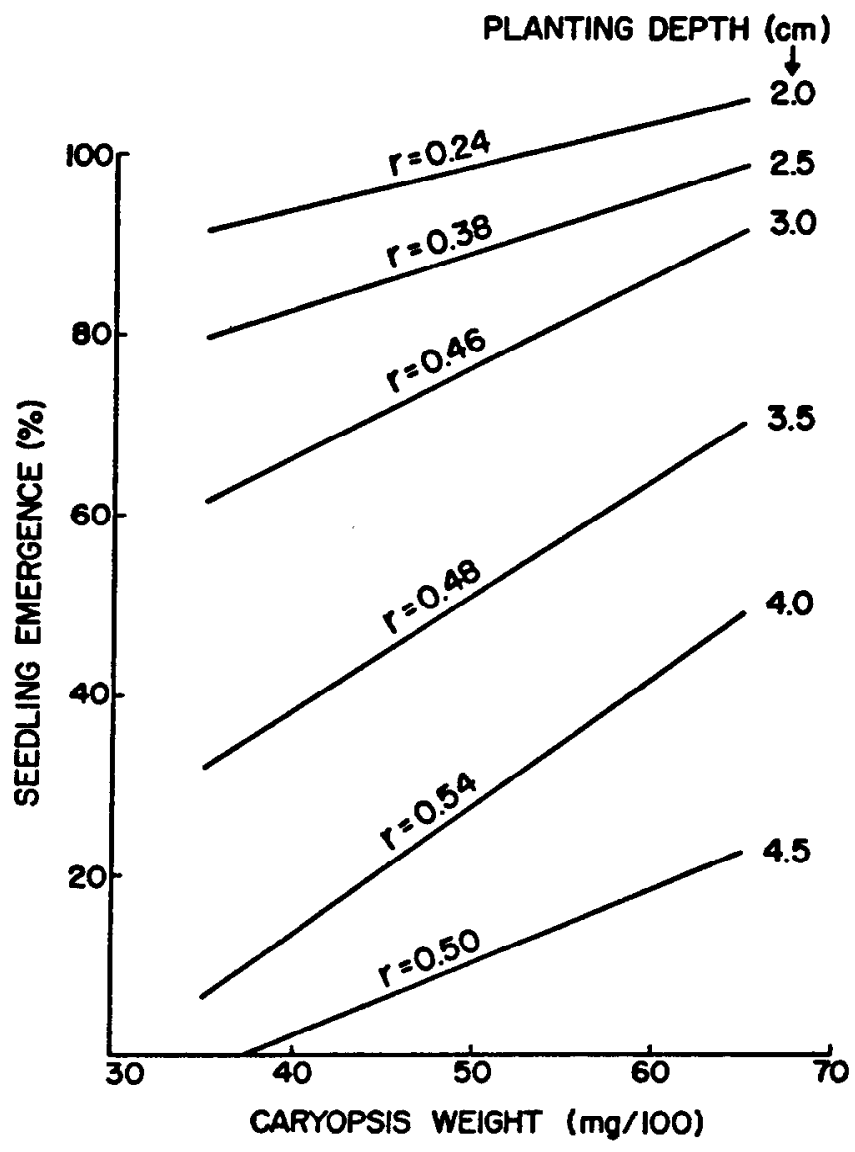

Fig. 2. Effects of caryopsis weight and planting depth on seedling emergence of blue grama seedlings grown under favorable soil moisture conditions. Differences among caryopsis weight means and planting depth means were significant $(\mathrm{p} \leq 0.01)$. The interaction of caryopsis weight and planting depth was significant $(\mathrm{p} \leq 0.01)$.

centage emergence was 0.73 when the percentage emergence for each parent plant was averaged over all planting depths. Analysis of covariance indicated that parent plants still had different emergence percentages after adjusting for the effects of caryopsis weight. These results and those of our other studies suggest that blue grama emergence could be improved by recurrent selection for high caryopsis weight and emergence from deep plantings.

The rate at which seedlings emerged was decreased with increased planting depth (from 24.5 to 17.3 emergence index), probably because of the greater distance the subcoleoptile internode had to elongate to elevate the coleoptile to the soil surface. There were no consistent trends in the effect of caryopsis weight on emergence index. The 3 accessions had emergence indices of 22.8 , 21.2, and 19.0 for PM-K-1483, Lovington, and Hachita, respectively.

Deep plantings were associated with lower shoot weights (Fig. 3 ), whereas heavier caryopses were associated with higher shoot weights and overcame the inhibitory effects of deep planting. Large caryopses may have both larger embryos and a greater amount of stored energy, which may result in larger first leaves. With the exponential growth typical of seedling leaf area, large caryopses may thus contribute to more rapid shoot growth. The 3 accessions differed in shoot weights with 254,242 , and $220 \mathrm{mg} /$ seedling for Hachita, Lovington, and PM-K-1483, respectively.

Planting depth had no significant effect on length of the longest adventitious root. Although there were differences among caryopsis weight classes for adventitious root length, there were no apparent trends. Mean adventitious root lengths among the 54 parent plants varied from 7.4 to $9.8 \mathrm{~cm}$ indicating potential for selection. 


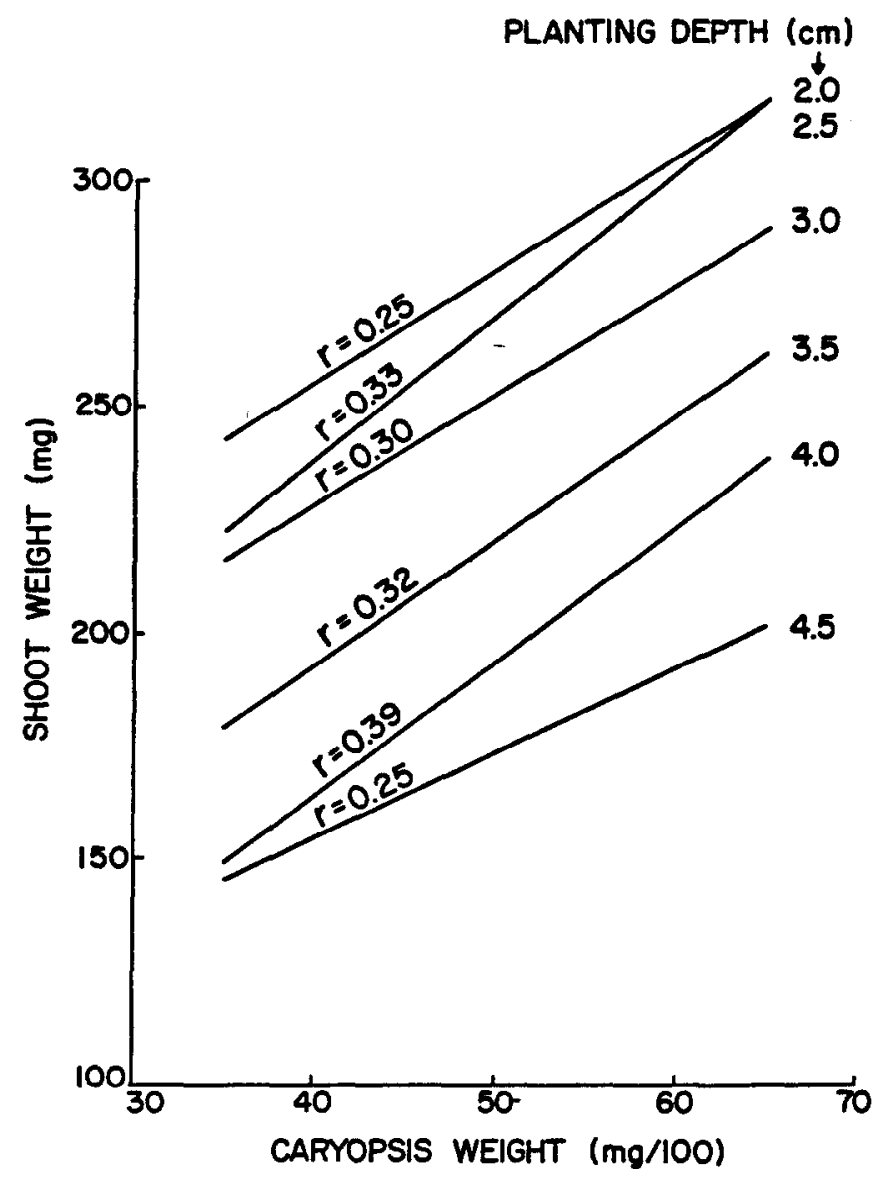

Fig. 3. Effects of caryopsis weight and planting depth on shoot weight of blue grama seedlings grown under favorable soil moisture conditions. Differences among caryopsis weight means and planting depth means were significant $(\mathrm{P} \leq 0.01)$. The interaction of caryopsis weight and planting depth was not significant $(\mathrm{P}>0.05)$.

Broad sense heritabilities for this characteristic were estimated at 0.80 in our other studies. Adventitious root lengths were uncorrelated with caryopsis weight. The 3 accessions tested had different $(P \leq 0.01)$ mean root lengths $(8.9,8.6$, and $8.1 \mathrm{~cm}$ for Hachita, Lovington, and PM-K-1483, respectively), which also suggests that root growth is under partial genetic control. Wilson et al. (unpubl. data) found a broad sense heritability of 0.17 for this trait among a group of highly selected progenies.

Greater planting depth was associated with a negative effect on adventitious root weight (Table 4). Adventitious root weight

Table 4. Effect of planting depth and caryopsis weight on adventitious root weight of blue grama seedlings grown under favorable soil moisture conditions.

\begin{tabular}{lcccccc}
\hline \hline & \multicolumn{6}{c}{ Planting Depth (cm) } \\
\cline { 2 - 7 } & 2.0 & 2.5 & 3.0 & 3.5 & 4.0 & 4.5 \\
\cline { 2 - 7 } $\begin{array}{l}\text { Adventitious root } \\
\text { wt. (mg) }\end{array}$ & 39.7 & 38.4 & 36.3 & 36.4 & 33.6 & 31.6 \\
& \multicolumn{5}{c}{ Caryopsis } & Weight Class \\
\cline { 2 - 7 } & 1 & 2 & 3 & 4 & 5 & 6 \\
\cline { 2 - 7 } $\begin{array}{l}\text { Adventitious } \\
\text { root wt. (mg) }\end{array}$ & 31.6 & 34.3 & 34.7 & 37.4 & 41.3 & 38.5 \\
\hline $\begin{array}{l}\text { 1Differences among planting depth means and weight class means were significant } \\
(p \leq 0.05 \text { and } \leq 0.01 \text {, respectively. }\end{array}$
\end{tabular}

increased as seed weight increased up to weight class 5 and then dropped off in class 6 (Table 4). It must be remembered that there was a genetic difference among weight classes because the seeds in each weight class came from different parent plants. The lower root weight for weight class 6 is therefore not necessarily associated with seed weight. Accessions differed $(P \leq 0.01)$ in adventitious root weight $(40.3,37.9$, and $31.0 \mathrm{mg} /$ seedling for Hachita, Lovington, and PM-K-1483, respectively).

\section{Path Coefficient Analysis}

Path coefficient analysis yielded statistically comparable standardized path coefficients ( $p$ ) for variables associated with adventitious root weight (Fig. 4). A direct causal effect and the postulated

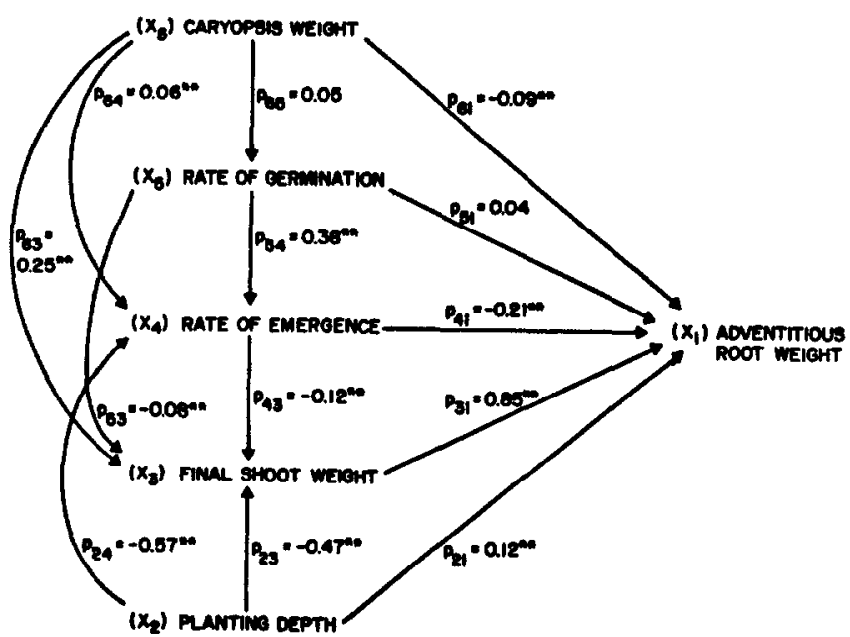

Fig. 4. Path coefficient diagram of relationships among growth variables in blue grama seedlings grown under favorable soil moisture conditions. ** Indicates significant path coefficients at $\mathrm{P} \leq 0.01$.

direction of that effect is shown by an arrow extending from the independent to the dependent variable. Independent variables may also exert indirect effects through their actions on other independent variables which are illustrated by alternative paths that connect the independent and dependent variables. The magnitude of the indirect effect is equal to the product of coefficients along the connecting paths.

The 4 most influential relationships revealed by the path coefficient analysis were the direct positive association of shoot weight with adventitious root weight $\left(P_{31}=0.85\right)$, the direct negative association of planting depth with rate of emergence $\left(P_{24}=-0.57\right)$, the direct negative effect of planting depth on shoot weight $\left(P_{23}=\right.$ -0.47 ), and the large indirect negative effect of planting depth on adventitious root weight through its effect on shoot weight $\left(P_{23} \times\right.$ $\left.P_{31}{ }^{\circ}-0.41\right)$.

Caryopsis weight had only a slight direct association with adventitious root weight $\left(P_{61}=-0.09\right)$. Caryopsis weight did have a positive total correlation with root weight $r=0.10$ through an increase in final shoot weight $\left(P_{63}=0.25\right)$, which in turn was associated with an increase in root weight $\left(P_{31}=0.85\right)$. It was unexpected that higher caryopsis weight did not result in an increase in the rate-of-emergence index and that earlier emergence was associated with a decrease in adventitious root weights.

The strongest association revealed in the path coefficient analysis was that heavier shoots were associated with heavier adventitious roots. Heavier caryopses did promote the desirable characteristic of heavier shoots. However, under the favorable moisture conditions of this experiment, deeper plantings were associated with decreased shoot weights and thereby root weights. A companion paper (Carren et al. 1987) describes results under less favorable moisture conditions. 


\section{Discussion and Conclusions}

The subcoleoptile internode of blue grama elongates in response to planting depth and elevates the coleoptile to near the soil surface (coleoptile node within 4 to $6 \mathrm{~mm}$ of surface) with only a slight increase (about $0.5 \mathrm{~mm}$ ) in coleoptile length. Weight per unit length of the subcoleoptile internode decreased in response to planting depth. If this parameter is indicative of xylem vessel diameter, deep plantings might result in seedlings with a slender subcoleoptile internode which could restrict water translocation from the seminal root to developing leaves. A decrease in the amount of water available to the shoot would cause a decrease in the maximum shoot weight that can be supported by the seminal root (Nason et al. 1987).

Although seminal root length decreased with increased planting depth, there was little difference in the actual depth of the root tip in the soil profile. The subcoleoptile internode increased in length about the same amount that the root decreased in length. Planting depth therefore had little adverse effect on depth of seminal roots. Differences among accessions and among caryopsis weight classes for seminal root length, shoot length, and coleoptile length suggest that these characteristics might be improved through breeding and selection. Under favorable soil moisture conditions, deep planting was not advantageous for emergence of seedling growth. Deep planting resulted in delayed emergence, decreased percentage emergence, and decreased shoot growth and root weight.

There was a clear advantage of high caryopsis weight for seedling establishment because high caryopsis weight was associated with increased emergence, shoot weight, and adventitious root weight. High caryopsis weight might overcome the disad vantages of deep planting and allow seeds to be placed in moist soil for germination and emergence. Because high shoot weight was highly correlated with high adventitious root weight, large caryopses could indirectly increase root growth through their positive effect on shoot growth. This could then lead to successful establishment of blue grama seedlings.

\section{Literature Cited}

Arnott, R.A. 1969. The effect of seed weight and depth of sowing on the emergence and early seedling growth of perennial rye grass. J. Brit. Grassland Soc. 24:104-1 10.

Bement, R.E., R.D. Barmington, A.C. Everson, L.O. Hylton, Jr., and E.E. Remmenga. 1965. Seeding of abandoned croplands in the Central Great Plains. J. Range Manage. 18:53-58.

Carren, C.J., A.M. Wilson, and R.L. Cuany. 1987. Effects of caryopsis weight and planting depth of blue grama II. Emergence in marginal soil moisture. J. Range Manage. 40:212-216.

Hyder, D.N., A.C. Everson, and R.E. Bement. 1971. Seedling morphology and seeding failures with blue grama. J. Range Manage. 24:287-292.

Kneebone, W.R., and C.L. Cremer. 1955. The relationship of seed size to seedling vigor in some native grass species. Agron. J. 47:472-477.

Knipe, O.D. 1970. Large seeds produce more, better alkali sacaton plants. J. Range Manage. 23:369-371.

Kotowski, F. 1926. Temperature relations to germination of vegetable seed. Amer. Soc. for Hort. Sci. 23:176-184.

Maguire, J.D. 1962. Speed of germination-aid in selecting for seedling emergence and vigor. Crop Sci. 2:176-177.

Nason, Debora, R.L. Cuany, and A.M. Wilson. 1987. Recurrent selection in blue grama I. Seedling water uptake and shoot weight. Crop Sci. 27: (in press)

Nie, N.H., C.H. Hull, J.C. Jenkins, K. Steinbrenner, and D.H. Bent. 1975. Path analysis and causal interpretation. p. 383-397. In: Statistical Package for the Social Sciences. McGraw-Hill Book Co., New York.

Rogler, G.A. 1954. Seed size and seedling vigor in crested wheatgrass. Agron. J. 46:216-220.

Tossell, W.E. 1960. Early seedling vigor and seed weight in relation to breeding in smooth bromegrass, Bromus inermis Leyss. Can. J. Plant Sci. 40:268-280.

Trupp, C.R., and I.T. Carlson. 1971. Improvement of seedling vigor of smooth bromegrass (Bromus inermis Leyss.) by recurrent selection for high seed weight. Crop Sci. 11:225-228.

Wilson, A.M., and D.D. Briske. 1979. Seminal and adventitious root growth of blue grama seedlings on the Central Plains. J. Range Manage. 32:209-213.

Wilson, A.M., R.L. Cuany, J.G. Fraser, and W.R. Oaks. 1981. Relationships among components of seed yield in blue grama. Agron. J. 73:1058-1062.

Wright, L.N. 1977. Germination and growth response of seed weight genotypes of Panicum antidotale Retz. Crop Sci. 17:176-178.

Wright, S. 1934. The method of path coefficients. Ann. Math. Stat. 5:161-214. 